\title{
Were VCF patients at higher risk of mortality following the 2009 publication of the vertebroplasty "sham" trials?
}

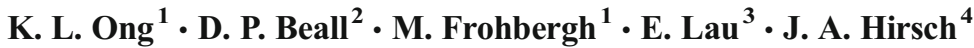

Received: 28 August 2017 / Accepted: 17 October 2017 /Published online: 24 October 2017

(C) The Author(s) 2017, corrected publication 2019

\begin{abstract}
Summary The 5-year period following 2009 saw a steep reduction in vertebral augmentation volume and was associated with elevated mortality risk in vertebral compression fracture (VCF) patients. The risk of mortality following a VCF diagnosis was $85.1 \%$ at 10 years and was found to be lower for balloon kyphoplasty (BKP) and vertebroplasty (VP) patients. Introduction BKP and VP are associated with lower mortality risks than non-surgical management (NSM) of VCF. VP versus sham trials published in 2009 sparked controversy over its effectiveness, leading to diminished referral volumes. We hypothesized that lower BKP/VP utilization would lead to a greater mortality risk for $\mathrm{VCF}$ patients.

Methods BKP/VP utilization was evaluated for VCF patients in the $100 \%$ US Medicare data set (2005-2014). Survival and morbidity were analyzed by the Kaplan-Meier method and compared between NSM, BKP, and VP using Cox regression with adjustment by propensity score and various factors.

Results The cohort included 261,756 BKP (12.6\%) and $117,232 \mathrm{VP}(5.6 \%)$ patients, comprising $20 \%$ of the VCF patient population in 2005, peaking at 24\% in 2007-2008, and declining to $14 \%$ in 2014 . The propensity-adjusted mortality risk for VCF patients was $4 \%(95 \% \mathrm{CI}, 3-4 \%$; $p<0.001$ ) greater in 2010-2014 versus 2005-2009. The 10year risk of mortality for the overall cohort was $85.1 \%$. BKP
\end{abstract}

K. L. Ong

kong@exponent.com

1 Exponent, Inc., 3440 Market St, Suite 600, Philadelphia, PA, USA

2 Oklahoma Spine, Edmond, OK, USA

3 Exponent, Inc., Menlo Park, CA, USA

4 Massachusetts General Hospital, Boston, MA, USA and VP cohorts had a 19\% (95\% CI, 19-19\%; $p<0.001)$ and $7 \%$ (95\% CI, 7-8\%; $p<0.001)$ lower propensity-adjusted 10 year mortality risk than the NSM cohort, respectively. The BKP cohort had a $13 \%(95 \%$ CI, $12-13 \%$; $p<0.001)$ lower propensity-adjusted 10-year mortality risk than the VP cohort. Conclusions Changes in treatment patterns following the 2009 VP publications led to fewer augmentation procedures. In turn, the 5-year period following 2009 was associated with elevated mortality risk in VCF patients. This provides insight into the implications of treatment pattern changes and associated mortality risks.

Keywords Balloon kyphoplasty $\cdot$ Mortality $\cdot$ Vertebral augmentation $\cdot$ Vertebral compression fracture .

Vertebroplasty

\section{Introduction}

Osteoporosis affects up to 12 million older adults in the USA, with an additional 47 million affected by low bone mass [1]. The number of older adults with osteoporosis or low bone mass is expected to increase in the USA by about 17 million (32\%) from 2010 to 2030 [2]. Spine fracture prevalence is approximately $5.4 \%$ in adults aged 40 years and older, increasing to $18 \%$ in those 80 years and older [3]. Vertebral compression fractures (VCFs) can lead to a downward spiral of symptoms and morbidity, from pain and disability to impaired pulmonary and respiratory function [4]. There are also associated mortality risks, with up to $72 \%$ mortality rate at 5 years [5] and $90 \%$ at 7 years [6].

Narcotic analgesics, back braces, and immobilization are common non-surgical means for VCF treatment, but may be poorly tolerated in elderly patients with side effects, such as constipation and increased risk of falls [7, 8]. Patients can also 
become dependent on opioids, which can be dangerous if misused [9]. Alternatively, surgical interventions with vertebroplasty (VP) or balloon kyphoplasty (BKP) can provide improved pain relief, functional recovery, and healthrelated quality of life [8, 10-13]. Moreover, lower mortality risks have been reported for augmentation over non-surgically managed (NSM) patients in the majority of claims-based studies [14-18]. A study of over one million elderly Medicare patients with VCFs, including over 75,000 VP and 140,000 BKP patients, described a 25 and $55 \%$ elevated mortality risk for NSM than VP and BKP, respectively [16].

In 2009, controversy sparked over the effectiveness of VP with publications by Kallmes et al. and Buchbinder et al., with approximately 200 patients in aggregate [19, 20]. Both identified no benefit in pain or functional improvements for VP over a "sham" procedure that included the periosteal injection of local anesthetic $[19,20]$. Yet periosteal local anesthetic infiltration can have a treatment effect, making it an active control [21]; this is one of the important differences in trial design between the 2009 trials and a more recent VP trial [8, 22]. A physician survey later showed that at least one of these two "sham" control studies was directly linked to reduced enthusiasm for VP referrals, even though most still felt that VP was an effective procedure in appropriate patients [23]. Nonetheless, the period following those publications exhibited diminished volumes of vertebral augmentation [23-26]. When taken in context of the trends in utilization of percutaneous interventional procedures for managing spinal pain [27, 28], the decrease is almost certainly the direct or indirect result of the two "sham" control studies.

With questions raised about the effectiveness of VP and the corresponding reductions in number of patients treated, this study addressed the following research questions: (1) What is the utilization of BKP/VP in the US elderly patient population? (2) Did the mortality risk for VCF patients differ between 2010 and 2014 and 2005-2009? (3) Are there differences in mortality and morbidity risks between BKP/VP and NSM patients?

\section{Methods}

The 100\% inpatient/outpatient Medicare claims data (20052014) was used to identify newly diagnosed VCF patients (International Classification of Diseases, Ninth Revision, Clinical Modification (ICD-9-CM) codes 733.13, 805.0, 805.2, 805.4, 805.6, and 805.8). The first VCF diagnosed in the study period was used; patients were required to have at least 12-month claims history prior to the VCF diagnosis to confirm a VCF-free period. Patients with BKP/VP in the 12 months before the index VCF were excluded. Those younger than 65 years old were also excluded due to potential confounding factors from their Medicare eligibility (certain disabilities, permanent kidney failure, amyotrophic lateral sclerosis, etc.). Patients enrolled in a Health Maintenance Organization plan (such as, Medicare Advantage plan), not enrolled in both Parts A and B of Medicare, not residing in the 50 states, and without 12 months of claims history prior to the VCF diagnosis were also excluded due to potential incompleteness in their claims history. The annual VCF incidence was determined from the number of newly diagnosed VCFs and Medicare enrollees. The patients were stratified into NSM, BKP, and VP cohorts. BKP/VP cohorts were those who underwent augmentation within the first year of the VCF diagnosis; those who underwent fusion surgery between the VCF diagnosis and BKP/VP were excluded. The NSM cohort comprised of patients who did not undergo augmentation or fusion during the study period, and those who only underwent augmentation or fusion 1+ years after the index VCF diagnosis. BKP was identified using ICD-9-CM code 81.66 or Current Procedural Terminology (CPT) codes 22289 and 22523-22525, while VP was identified using ICD-9-CM 81.65 or CPT codes 22520-22522. Spine fusion was identified using ICD-9-CM codes 81.61, 84.51, 81.00$81.08,81.30-81.39$ or CPT codes 22532-22534, 22548, 22554, 22556, 22558, 22585, 22590, 22595, 22600, 22610, 22612, 22614, 22630, 22632, 22800, 22802, 22804, 22808, $22810,22812,22840-22847,22849$, and 22851. This study was based on publicly available data sets, did not use private health identifiable information, and did not represent human subject research, and therefore did not require oversight by our institutional review boards.

Mortality was the primary outcome, based on the date of death from the Medicare denominator file, which contains enrollment and eligibility information. Mortality with pneumonia diagnosed as a principal diagnosis or any (principal or secondary) diagnosis within 90 days prior to death was also determined. Morbidity conditions examined in this study included myocardial infarction/cardiac complications (ICD-9CM codes 410, 997.1), deep venous thrombosis $(451,453)$, infection (diagnosis 996.67, 999.3, 998.5; procedure, ICD-9CM codes $77.69,86.22,86.28$ or CPT codes 10180,22010 , 22015), pulmonary embolism $(415.11,415.19)$, pneumonia (480-487), urinary tract infection $(595.0,595.2,595.3$, $595.8,595.89,595.9,599.0,996.64)$, pulmonary/respiratory complications (490-496, 510-519), and readmissions. All outcomes were evaluated at up to 10 years follow-up, while readmissions were evaluated up to 1 year to limit the effects from other unrelated interventions. The length of stay (LOS) and discharge status following the first VCF hospitalization for the NSM cohort and the index augmentation surgery for the BKP and VP cohorts (inpatients) were compared.

Mortality for VCF patients between the 2005-2009 and 2010-2014 time periods was compared using multivariate Cox regression, adjusting for propensity score, gender, age, race, census region, socioeconomic status, comorbidities, type 
of fracture (traumatic or pathologic), fracture location (cervical, thoracic, lumbar, sacrum), initial VCF diagnosis site of service (inpatient, outpatient), physician specialty for initial VCF diagnosis, and treatment group (NSM, BKP, VP). Socioeconomic status was based on whether the patient's Medicare premiums/deductibles were state subsidized (Medicare buy-in status), as well as the per capita income for the patient's county of residence. Comorbidities were determined using the Charlson score [29] and the diagnosis of 12 specific comorbid conditions in the 12 months prior to the VCF. The specific comorbid conditions comprised: (1) arterial disease (ICD-9-CM codes 440-448), (2) chronic obstructive pulmonary disease (490-496), 3) cancer (140-176, 179-208, 210-239, V10), (4) diabetes (250), (5) hip fracture (820), (6) hypertensive disease (401-405), (7) ischemic heart disease (410-414), (8) other heart disease (420-429), (9) pneumonia (480-487, V12.6), (10) pulmonary heart disease (415-417, V12.5), (11) stroke (430-438), and (12) wrist fracture $(813.4,813.5,814.0,814.1)$. Propensity score was derived for the probability of undergoing augmentation, using logistic regression conditional on gender, age, race, census region, socioeconomic status, comorbidities, type of fracture, diagnosis of osteoporosis, fracture location, initial VCF diagnosis site of service, physician specialty for initial VCF diagnosis, year, and two-way interactions for all the above covariates (except per capita income and physician specialty). Statistical comparisons of the mortality and morbidity conditions were also compared between the study cohorts, using propensity-adjusted, multivariate Cox regression. The covariates were the same as above, except time period (2005-2009 vs. 2010-2015) was replaced with year as a continuous variable.

\section{Results}

Our study identified 2,129,769 newly diagnosed VCF patients. VCF prevalence was 239,325 in 2005 , and then declined to 200,595 in 2010 , before increasing to 209,337 in 2014. After accounting for the annual Medicare population, VCF incidence decreased from 74.7 to 62.0 VCFs per ten thousand enrollees between 2005 and 2014. During 2005 to 2008, VP volume ranged between 16,258 and 16,858 annually, but declined from 15,742 procedures in 2009 to 8419 procedures in 2014. BKP volume increased from 16,704 in 2005 to 33,648 in 2008 before experiencing a less steep volume reduction from 32,715 in 2009 to 29,679 in 2014. Vertebral augmentation patients comprised $20 \%$ of the VCF population in 2005 , peaked at $24 \%$ in $2007-2008$, and declined to $14 \%$ in 2014. After excluding patients who were treated with fusion within a year after VCF, including between VCF and BKP/VP, the final study cohort included 2,077,944 VCF patients $(n=261,756 \operatorname{BKP}(12.6 \%)$ and $117,232 \mathrm{VP}(5.6 \%))$.
Among the VCF study cohort, hypertensive disease and other heart disease were the most commonly diagnosed comorbidities (Fig. 1). Close to half the patients were also diagnosed with ischemic heart disease and cancer. NSM patients did not have a higher prevalence of comorbidities than the augmented patients. Baseline demographics of the three cohorts are provided in Table 1.

Mortality risk for the overall VCF cohort was $85.1 \%(95 \%$ CI, 84.7-85.5\%) at 10 years (Fig. 2). When comparing time periods, the propensity-adjusted mortality risk for VCF patients was $4 \%(95 \%$ CI, 3-4\%; $p<0.001)$ greater in 2010 2014 than 2005-2009. Additional factors associated with increased mortality risk included older age, higher Charlson score, cervical or thoracic fractures, lower socioeconomic status (household income and buy-in status), those diagnosed in an inpatient setting, Caucasians, patients in the South, males, non-surgical managed patients, diagnosed pathologic fractures, as well as history of other heart diseases, and pneumonia (all $p<0.001$ ). Following stratification by treatment group, the NSM cohort had 24\% (95\% CI, 23-24\%; $p<0.001)$ and $8 \%$ (95\% CI, 8-9\%; $p<0.001)$ higher propensity-adjusted 10year mortality risks than the BKP and VP cohorts, respectively (Fig. 3). In other words, the BKP and VP cohorts had a 19\% (95\% CI, 19-19\%; $p<0.001)$ and 7\% (95\% CI, 7-8\%; $p<0.001)$ lower propensity-adjusted 10-year mortality risk than the NSM cohort, respectively. The BKP cohort had a $13 \%$ (95\% CI, 12-13\%; $p<0.001$ ) lower propensityadjusted 10-year mortality risk than the VP cohort. These were still statistically different at earlier time points. For 10-year mortality risk with pneumonia as a principal diagnosis within 90 days prior to death, the NSM cohort had 19\% (95\% CI, 17$20 \% ; p<0.001)$ and $8 \%(95 \%$ CI, 6-10\%; $p<0.001)$ higher risks than the $\mathrm{BKP}$ and $\mathrm{VP}$ cohorts, respectively, while the BKP cohort had a $9 \%(95 \%$ CI, 7-10\%) lower risk than the VP cohort. For 10-year mortality risk with pneumonia as a principal/secondary diagnosis within 90 days prior to death, the NSM cohort had 21\% (95\% CI, 20-22\%; $p<0.001)$ and $3 \%$ (95\% CI, 2-4\%; $p<0.001)$ higher risks than the BKP and VP cohorts, respectively, while the BKP cohort had a $15 \%$ (95\% CI, 14-16\%; $p<0.001$ ) lower risk than the VP cohort.

The propensity-adjusted risk of readmissions and morbidities including cardiac complications, pulmonary embolism, pneumonia, deep venous thrombosis, urinary tract infection, and pulmonary/respiratory complications were significantly higher for the NSM cohort than BKP cohort at all time points (Fig. 4). At 1 year, outcomes with at least $10 \%$ greater risk for NSM than BKP patients were cardiac complications $(19 \%$; 95\% CI, $17-21 \% ; p<0.001)$ and pneumonia $(23 \% ; 95 \%$ CI, 22-24\%; $p<0.001)$. Compared to the VP cohort, the NSM cohort also had significantly higher propensityadjusted risk of cardiac complications, pneumonia, and urinary tract infection at all time points, but had significantly lower risk of pulmonary embolism and readmission. The 
Fig. 1 Prevalence of comorbidities in the 12 months prior to VCF diagnosis

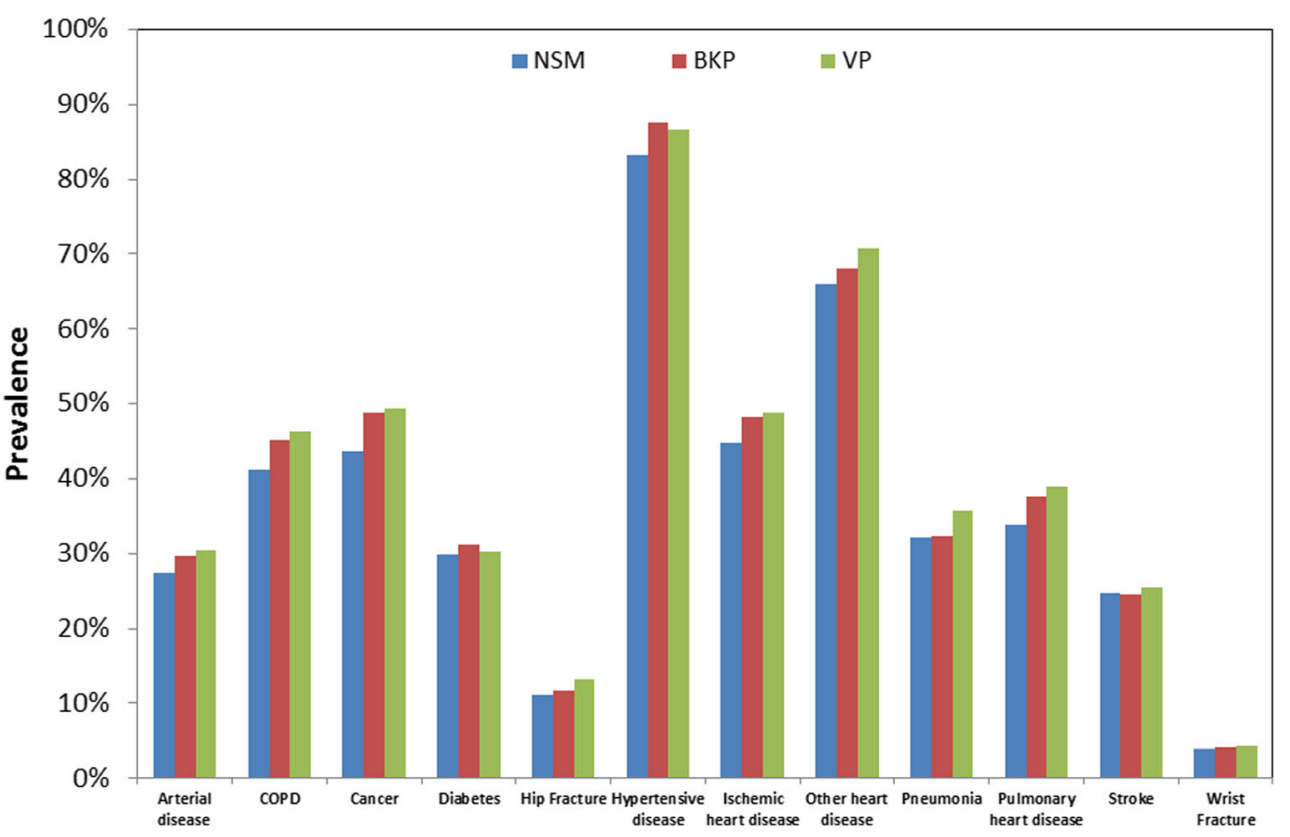

propensity-adjusted risk of readmission, pulmonary embolism, pneumonia, deep venous thrombosis, and pulmonary/ respiratory complications were significantly lower for BKP than VP cohorts at all time points. The mean LOS for hospitalized NSM, BKP, and VP patients were 5.2 days ( \pm 4.5 days),

Table 1 Baseline demographics of NSM, BKP, and VP patients

$\begin{array}{lll}\text { Non-operated } & \text { Balloon } & \text { Vertebroplasty } \\ (n=1,698,956) & \text { kyphoplasty } & (n=117,232) \\ (\%) & (n=261,756) & (\%) \\ & (\%) & \end{array}$

\begin{tabular}{lrrr}
\hline \% female & 70.2 & 72.5 & 73.1 \\
White & 91.8 & 94.6 & 95.1 \\
Black & 3.2 & 1.6 & 1.5 \\
Others & 4.9 & 3.8 & 3.4 \\
65-69 years old & 12.3 & 11.8 & 10.5 \\
70-74 years old & 14.7 & 16.2 & 14.8 \\
75-79 years old & 18.8 & 21.8 & 21.0 \\
80-84 years old & 22.4 & 24.7 & 24.9 \\
$\geq 85$ years old & 31.9 & 25.5 & 28.9 \\
Midwest & 26.4 & 23.3 & 34.9 \\
Northeast & 18.8 & 13.7 & 9.8 \\
South & 36.9 & 50.2 & 38.8 \\
West & 17.9 & 12.8 & 16.5 \\
Charlson index & 32.7 & 32.8 & 32.8 \\
$\quad 0$ & & & \\
1-2 & 38.5 & 39.0 & 38.8 \\
3-4 & 16.6 & 16.5 & 16.7 \\
$\geq 5$ & 12.2 & 11.7 & 11.7 \\
\% with & 17.4 & 12.3 & 11.7 \\
Medicare & & & \\
buy-in & & & \\
\hline
\end{tabular}

5.4 days ( \pm 5.1 days), and 6.6 days ( \pm 5.5 days), respectively. Although the average LOS appeared similar between the NSM and BKP cohorts, after adjusting for various patient and clinical factors, BKP patients were found to have significantly longer LOS by $18 \%(95 \%$ CI, $18-19 \% ; p<0.001)$ (Table 2). The VP cohort also had significantly longer adjusted LOS than the NSM cohort by 36\% (95\% CI, 35-37\%; $p<0.001)$, while the BKP cohort had shorter adjusted LOS than the VP cohort by $13 \%(95 \%$ CI, $13-13 \%$; $p<0.001)$. More than half of the BKP patients $(56.9 \%)$ were discharged to home, when compared to the VP (47.0\%) and NSM $(33.7 \%)$ cohorts. Nearly half of the NSM patients were discharged to skilled nursing facilities (48.0\%), compared to $31.0 \%$ of BKP and $39.6 \%$ of VP patients. After adjusting for patient and clinical factors, BKP patients were more than twice as likely to be discharged to home than NSM patients (odds ratio 2.27; 95\% CI, 2.20-2.35; $p<0.001$ ) (Table 2). BKP patients were $22 \%$ (95\% CI, 19-25\%; $p<0.001)$ more likely to be discharged to home than VP patients, while VP patients were, in turn, 86\% (95\% CI, 80-93\%; $p<0.001)$ more likely to be discharged to home than NSM patients.

\section{Discussion}

This analysis of over two million VCF patients in the US Medicare population showed that the 10-year mortality risk was exceptionally high at $85 \%$. The NSM cohort had 24 and $8 \%$ greater 10 -year mortality risks than the BKP and VP cohorts, respectively, and the BKP cohort also had a $13 \%$ lower 10 -year mortality risk than the VP cohort. Vertebral augmentation utilization peaked at $24 \%$ in $2007-2008$ and then 
Fig. 2 Overall survival of VCF patients

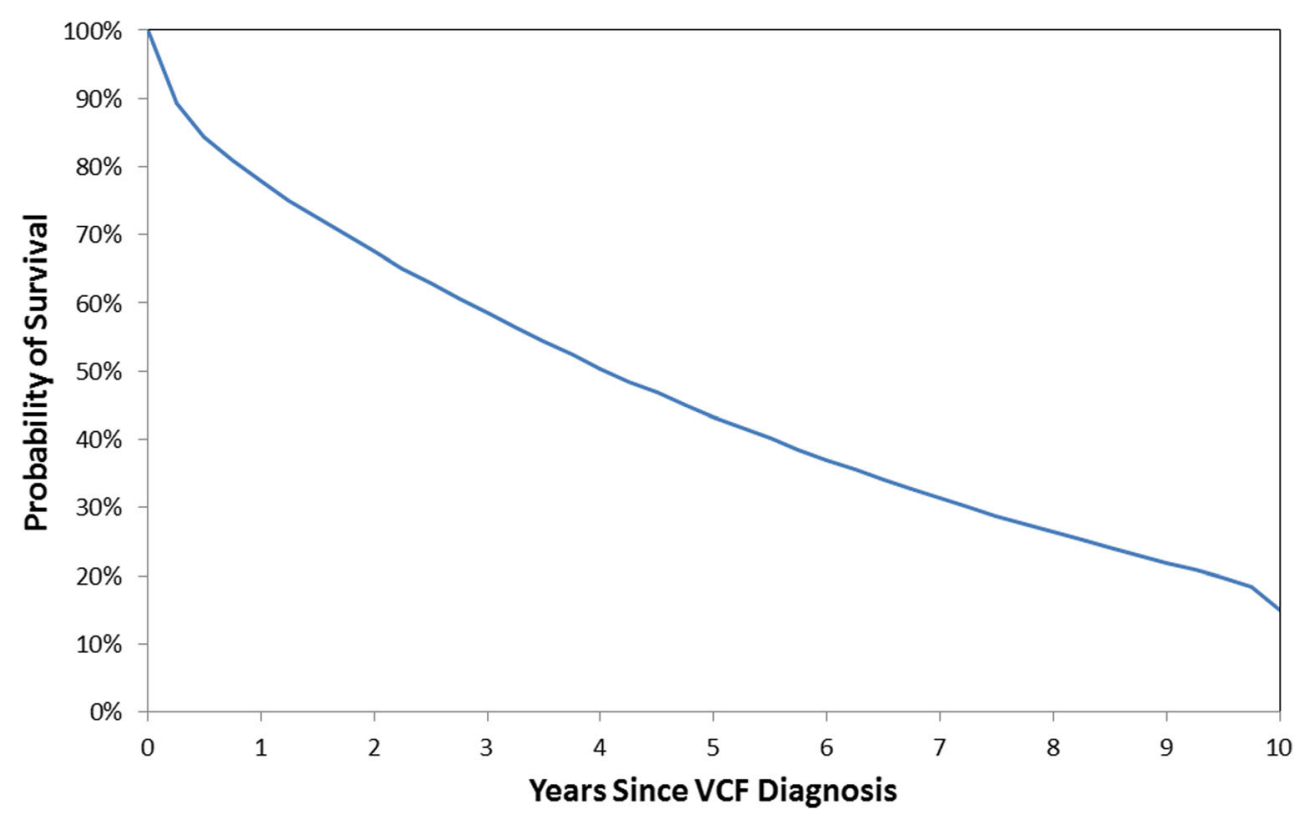

declined to $14 \%$ in 2014 . The mortality risk for VCF patients was also significantly greater in 2010-2014 than 2005-2009.

Vertebral augmentation in the Medicare population was noted to decline from 2009 onwards, although this impacted VP more dramatically. Researchers [23, 25] have attributed diminished VP volumes to the controversy sparked by the 2009 "sham" control publications [19, 20]. Others [30] have also pointed to insurance coverage changes or recommendations from professional societies, such as the American Academy of Orthopaedic Surgeons (AAOS) guidelines, which were impacted by the two aforementioned studies [31]. Despite the reduced volume, augmentation continues to be offered to many patients, which could reflect the difficulties faced by clinicians in reconciling the findings from the 2009 "sham" control papers and their clinical experience of patient improvements [32]. There is substantial evidence supporting the use of augmentation [8, 10-13, 33]. A lead site in one of the 2009 "sham" control studies also continued to perform VP relatively frequently, indicating "our [their] own belief in the efficacy of the procedure outweighs its risks" [25].

Consistent with earlier time periods [24, 26, 30], this present analysis of the Medicare population showed continued decline in BKP/VP utilization from 2009 through 2014, which indicated that relatively more VCF patients in the latter half of the study period were being non-surgically managed. Since previous studies have predominantly shown survival benefits from augmentation [14-18], patients in the latter half of the study period may be at higher risk of death. This was confirmed with the significantly higher 5-year mortality risk for VCF patients from 2010 to 2014 than 2005-2009. Moreover, VP and BKP cohorts had significantly lower propensityadjusted mortality risks than the NSM cohort at up to 10 years,
Fig. 3 Relative risk of mortality (propensity-adjusted) between NSM, BKP, and VP cohorts $(p<0.001$ for all $)$

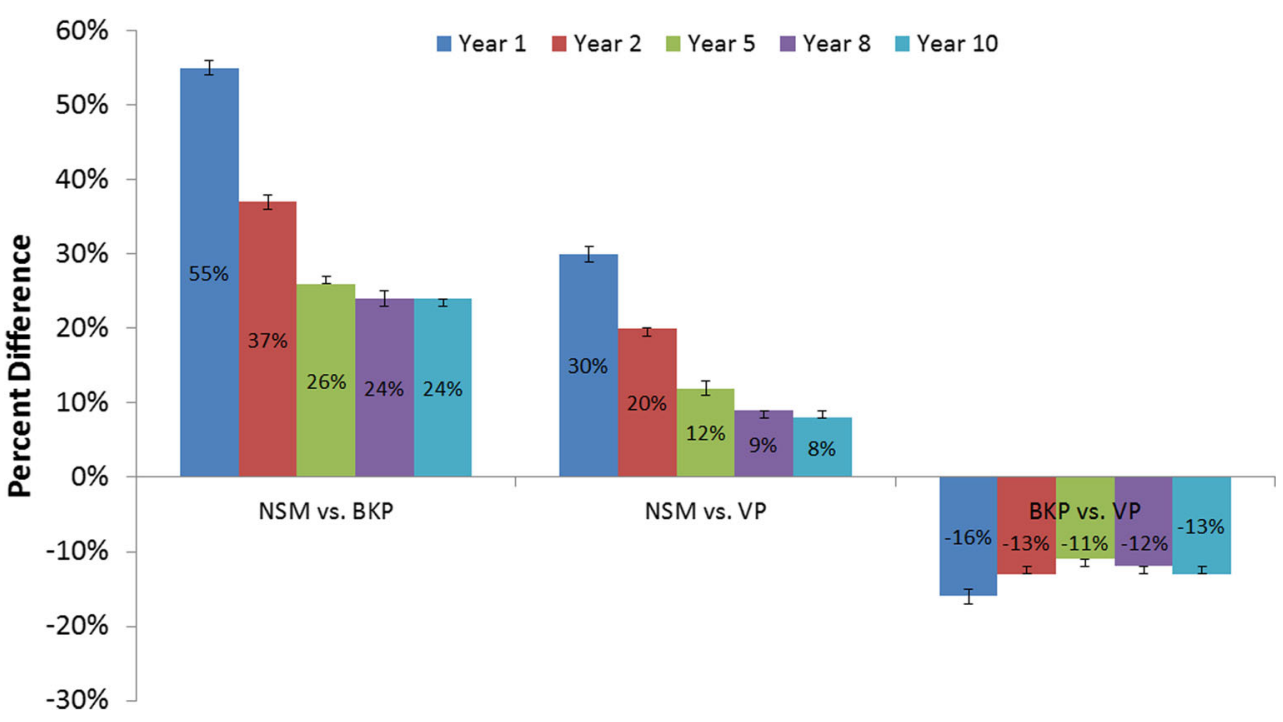



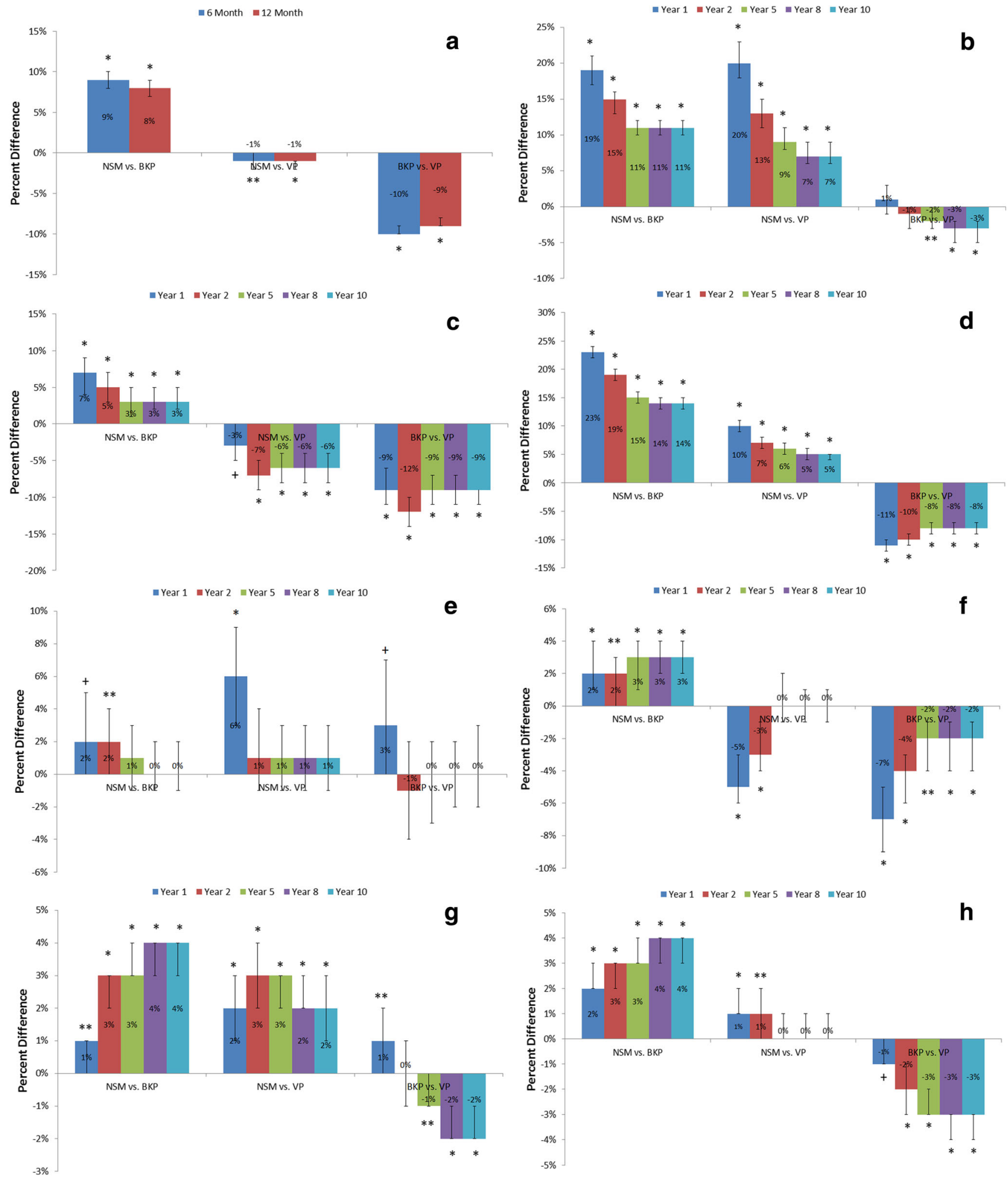

Fig. 4 Relative propensity-adjusted risks of readmission (a), cardiac complications (b), pulmonary embolism (c), pneumonia (d), infection (e), DVT (f), UTI (g), and pulmonary/respiratory complications (h) between NSM, BKP, and VP cohorts $\left({ }^{*} p<0.001 ; * *<<0.01 ;+p<0.05\right)$

a much longer follow-up than previous studies [14-18]. Those previous mortality studies also showed improved survival for BKP/VP over NSM [14-17], except for one by McCullough et al. [18], who reported lower adjusted mortality risks at 30 days and 1 year for augmented patients, but only at 30 days after propensity score matching. 
Table 2 Comparison of LOS and discharge to home (propensityadjusted)

\begin{tabular}{llllll}
\hline Treatment group & Reference group & LOS ratio & Lower limit & Upper limit & $p$ value \\
BKP & Non-operated & 1.18 & 1.18 & 1.19 & $<0.001$ \\
VP & Non-operated & 1.36 & 1.35 & 1.37 & $<0.001$ \\
BKP & VP & 0.87 & 0.87 & 0.87 & $<0.001$ \\
Treatment group & Reference group & Discharge-to-home ratio & Lower limit & Upper limit & $p$ value \\
BKP & Non-operated & 2.27 & 2.20 & 2.35 & $<0.001$ \\
VP & Non-operated & 1.86 & 1.80 & 1.93 & $<0.001$ \\
BKP & VP & 1.22 & 1.19 & 1.25 & $<0.001$ \\
\hline
\end{tabular}

This study found that LOS was longer for hospitalized augmented patients than NSM patients, but the augmented patients had a higher likelihood of being discharged to home. VP patients were also more likely to have longer LOS and less likely to be discharged to home than BKP. Notably, the opposite trends in the LOS and home discharge rates appears to reflect a shifting of the NSM patients from the inpatient to other facilities, and do not reflect recovery of the patients. Any perceived cost savings from the 0.2 days shorter LOS, on average, for the NSM cohort over the BKP cohort was outweighed by close to twice as few NSM patients being discharged to home. In contrast to this study, Chen and coworkers [14] observed shorter LOS for BKP patients than NSM patients, but this could be due to the different study periods. The Chen study utilized Medicare data from 2006, whereas this analysis observed some temporal changes in LOS during the study period; the average LOS for the BKP cohort increased between 2005 and 2009 and then remained relatively stable. Both the Chen study and this present analysis reported LOS for inpatients, which likely reflects the experience for sicker patients, but did not include outpatients, which would have lowered the overall LOS.

This study has several limitations. Although the present analysis focused on mortality and morbidity risks, outcomes, such as pain relief or quality of life, could not be assessed due to inherent limitations of claims data. The effects of several comorbidities, including previous diagnosis of hip or wrist fractures, were considered in the analysis, but other clinical variables or baseline health conditions, such as fracture severity and severity of the underlying osteoporosis, which are not captured in the database, may have potential confounding effects. This study was also unable to determine the criteria for referrals to BKP and VP compared to NSM. Because the NSM cohort was discharged to nursing facilities at a significantly higher rate than BKP and VP cohorts, the present analysis could not accurately assess the LOS between the three cohorts. The cause of death is unknown in the data set, but various morbidities and mortality with pneumonia diagnosed in the 90 days prior to death were used to provide some insight into the health status leading to expiration. There may be potential for selection bias due to the observational study design, which this study attempted to minimize by controlling for a large number of confounding factors and propensity scoring. On the other hand, this study provides real-world outcomes for a large population of over two million VCF patients, which is not feasible through a randomized controlled trial. The Medicare claims data also provides consistency of follow-up because loss of "enrollment" would only occur through death.

\section{Summary}

There has been extensive debate following publication of two 2009 "sham" control studies. Many medical societies have supported the continued use of augmentation as a safe and efficacious procedure for symptomatic VCFs [34] or as being reasonable options for selected patients [35], but the AAOS strongly recommended against VP and provided limited recommendation for BKP [31]. National treatment guidelines or technology assessments have also been mixed [36-38]. Based on this present analysis of over two million VCF patients in the Medicare population, publication of the 2009 "sham" control studies likely resulted in lower augmentation utilization, and in turn, the 5-year period following 2009 was associated with elevated mortality risk in VCF patients. These findings provide real-world insight into the implications of shifts in treatment patterns and associated mortality risks for VCF patients.

Funding statement Exponent received funding from Medtronic for this study. Medtronic provided minimal input into the design of the study, but played no role in the collection, management, analysis, and interpretation of the data and preparation of the manuscript. Medtronic reviewed the manuscript editorially.

\section{Compliance with ethical standards}

Conflicts of interest KLO, EL, MF: employees of Exponent, Inc., a scientific and engineering consulting firm.

KLO: Exponent has been paid fees by companies and suppliers for my consulting services on behalf of such companies and suppliers (Stryker Orthopaedics, Zimmer Biomet, Ethicon, Ferring Pharmaceuticals, Paradigm Spine, Medtronic, Pacira Pharmaceuticals, DJO, Ossur).

JAH: direct fees consulting (Medtronic; Globus (one-time fee)); Codman Neurovascular Data and Safety Monitoring Board participation. 
DPB: Benvenue: paid consultant; paid presenter or speaker; stock or stock options.

Lilly: paid presenter or speaker.

Lilly, Amendia, Medtronic: board or committee member; paid consultant; research support; stock or stock options.

Medtronic: paid presenter or speaker.

SIR: board or committee member.

Vexim: board or committee member; stock or stock options.

EL: Exponent has been paid fees by companies and suppliers for my consulting services onbehalf of such companies and suppliers (Stryker Orthopaedics, Ferring Pharmaceuticals, Medtronic, CeramTec).

Statement of human and animal rights This study was based on publicly available data sets, did not use private health identifiable information, and did not represent human subject research, and therefore did not require oversight by our institutional review boards.

The manuscript does not contain any studies with human participants or animals performed by any of the authors. For this type of retrospective study, formal consent is not required.

Open Access This article is distributed under the terms of the Creative Commons Attribution 4.0 International License (http://creativecommons.org/ licenses/by/4.0/), which permits use, duplication, adaptation, distribution and reproduction in any medium or format, as long as you give appropriate credit to the original author(s) and the source, provide a link to the Creative Commons license and indicate if changes were made.

\section{References}

1. Looker AC, Sarafrazi Isfahani N, Fan B, Shepherd JA (2017) Trends in osteoporosis and low bone mass in older US adults, 2005-2006 through 2013-2014. Osteoporos Int. https://doi.org/10. 1007/s00198-017-3996-1

2. Wright NC, Looker AC, Saag KG, Curtis JR, Delzell ES, Randall S, Dawson-Hughes B (2014) The recent prevalence of osteoporosis and low bone mass in the United States based on bone mineral density at the femoral neck or lumbar spine. J Bone Mineral Res 29(11):2520-2526. https://doi.org/10.1002/jbmr.2269

3. Cosman F, Krege JH, Looker AC, Schousboe JT, Fan B, Sarafrazi Isfahani N, Shepherd JA, Krohn KD, Steiger P, Wilson KE, Genant HK (2017) Spine fracture prevalence in a nationally representative sample of US women and men aged $\geq 40$ years: results from the National Health and Nutrition Examination Survey (NHANES) 2013-2014. Osteoporos Int. https://doi.org/10.1007/s00198-0173948-9

4. Old JL, Calvert M (2004) Vertebral compression fractures in the elderly. Am Fam Physician 69(1):111-116

5. Johnell O, Kanis JA, Oden A, Sernbo I, Redlund-Johnell I, Petterson C, De Laet C, Jonsson B (2004) Mortality after osteoporotic fractures. Osteoporos Int 15(1):38-42. https://doi.org/10. 1007/s00198-003-1490-4

6. Lau E, Ong K, Kurtz S, Schmier J, Edidin A (2008) Mortality following the diagnosis of a vertebral compression fracture in the Medicare population. J Bone Joint Surg Am 90(7):1479-1486. https://doi.org/10.2106/JBJS.G.00675

7. Goldstein CL, Chutkan NB, Choma TJ, Orr RD (2015) Management of the elderly with vertebral compression fractures. Neurosurgery 77(Suppl 4):S33-S45. https://doi.org/10.1227/NEU. 0000000000000947
8. Clark W, Bird P, Gonski P, Diamond TH, Smerdely P, McNeil HP, Schlaphoff G, Bryant C, Barnes E, Gebski V (2016) Safety and efficacy of vertebroplasty for acute painful osteoporotic fractures (VAPOUR): a multicentre, randomised, double-blind, placebocontrolled trial. Lancet 388(10052):1408-1416. https://doi.org/10. 1016/S0140-6736(16)31341-1

9. Wilson-Poe AR, Moron JA (2017) The dynamic interaction between pain and opioid misuse. Br J Pharmacol. https://doi.org/10. 1111/bph.13873

10. Berenson J, Pflugmacher R, Jarzem P, Zonder J, Schechtman K, Tillman JB, Bastian L, Ashraf T, Vrionis F, Cancer Patient Fracture

Evaluation I (2011) Balloon kyphoplasty versus non-surgical fracture management for treatment of painful vertebral body compression fractures in patients with cancer: a multicentre, randomised controlled trial. The Lancet Oncology 12(3):225-235. https://doi. org/10.1016/S1470-2045(11)70008-0

11. Boonen S, Van Meirhaeghe J, Bastian L, Cummings SR, Ranstam J, Tillman JB, Eastell R, Talmadge K, Wardlaw D (2011) Balloon kyphoplasty for the treatment of acute vertebral compression fractures: 2-year results from a randomized trial. J Bone Mineral Res 26(7):1627-1637. https://doi.org/10.1002/jbmr.364

12. Klazen CA, Lohle PN, de Vries J, Jansen FH, Tielbeek AV, Blonk MC, Venmans A, van Rooij WJ, Schoemaker MC, Juttmann JR, Lo TH, Verhaar HJ, van der Graaf Y, van Everdingen KJ, Muller AF, Elgersma OE, Halkema DR, Fransen H, Janssens X, Buskens E, Mali WP (2010) Vertebroplasty versus conservative treatment in acute osteoporotic vertebral compression fractures (Vertos II): an open-label randomised trial. Lancet 376(9746):1085-1092. https:// doi.org/10.1016/S0140-6736(10)60954-3

13. Wardlaw D, Cummings SR, Van Meirhaeghe J, Bastian L, Tillman JB, Ranstam J, Eastell R, Shabe P, Talmadge K, Boonen S (2009) Efficacy and safety of balloon kyphoplasty compared with nonsurgical care for vertebral compression fracture (FREE): a randomised controlled trial. Lancet 373(9668):1016-1024. https:// doi.org/10.1016/S0140-6736(09)60010-6

14. Chen AT, Cohen DB, Skolasky RL (2013) Impact of nonoperative treatment, vertebroplasty, and kyphoplasty on survival and morbidity after vertebral compression fracture in the medicare population. J Bone Joint Surg Am 95(19):1729-1736. https://doi.org/10.2106/ JBJS.K.01649

15. Edidin AA, Ong KL, Lau E, Kurtz SM (2011) Mortality risk for operated and nonoperated vertebral fracture patients in the medicare population. J Bone Mineral Res 26(7):1617-1626. https://doi.org/ 10.1002/jbmr.353

16. Edidin AA, Ong KL, Lau E, Kurtz SM (2015) Morbidity and mortality after vertebral fractures: comparison of vertebral augmentation and nonoperative management in the Medicare population. Spine 40(15): 1228-1241. https://doi.org/10.1097/BRS.0000000000000992

17. Lange A, Kasperk C, Alvares L, Sauermann S, Braun S (2014) Survival and cost comparison of kyphoplasty and percutaneous vertebroplasty using German claims data. Spine 39(4):318-326. https://doi.org/10.1097/BRS.0000000000000135

18. McCullough BJ, Comstock BA, Deyo RA, Kreuter W, Jarvik JG (2013) Major medical outcomes with spinal augmentation vs conservative therapy. JAMA Intern Med 173(16):1514-1521. https:// doi.org/10.1001/jamainternmed.2013.8725

19. Buchbinder R, Osborne RH, Ebeling PR, Wark JD, Mitchell P, Wriedt C, Graves S, Staples MP, Murphy B (2009) A randomized trial of vertebroplasty for painful osteoporotic vertebral fractures. $\mathrm{N}$ Engl J Med 361(6):557-568. https://doi.org/10.1056/ NEJMoa0900429

20. Kallmes DF, Comstock BA, Heagerty PJ, Turner JA, Wilson DJ, Diamond TH, Edwards R, Gray LA, Stout L, Owen S, Hollingworth W, Ghdoke B, Annesley-Williams DJ, Ralston SH, Jarvik JG (2009) A randomized trial of vertebroplasty for osteoporotic spinal fractures. N Engl J Med 361(6):569-579. https://doi. org/10.1056/NEJMoa0900563 
21. Wilson DJ, Owen S, Corkill RA (2011) Facet joint injections as a means of reducing the need for vertebroplasty in insufficiency fractures of the spine. Eur Radiol 21(8):1772-1778. https://doi.org/10. 1007/s00330-011-2115-5

22. Hirsch JA, Chandra RV (2016) Resurrection of evidence for vertebroplasty? Lancet 388(10052):1356-1357. https://doi.org/10. 1016/S0140-6736(16)31356-3

23. Lindsey SS, Kallmes DF, Opatowsky MJ, Broyles EA, Layton KF (2013) Impact of sham-controlled vertebroplasty trials on referral patterns at two academic medical centers. PRO 26(2):103-105

24. Hirsch JA, Chandra RV, Pampati V, Barr JD, Brook AL, Manchikanti L (2016) Analysis of vertebral augmentation practice patterns: a 2016 update. J Neurointerventional Surg. https://doi.org/ 10.1136/neurintsurg-2016-012767

25. Luetmer MT, Kallmes DF (2011) Have referral patterns for vertebroplasty changed since publication of the placebocontrolled trials? AJNR Am J Neuroradiol 32(4):647-648. https:// doi.org/10.3174/ajnr.A2371

26. Manchikanti L, Pampati V, Hirsch JA (2013) Analysis of utilization patterns of vertebroplasty and kyphoplasty in the Medicare population. J Neurointerventional Surg 5(5):467-472. https://doi.org/10. 1136/neurintsurg-2012-010337

27. Manchikanti L, Pampati V, Hirsch JA (2016) Utilization of interventional techniques in managing chronic pain in Medicare population from 2000 to 2014: an analysis of patterns of utilization. Pain Physician 19(4):E531-E546

28. Manchikanti L, Pampati V, Hirsch JA (2016) Retrospective cohort study of usage patterns of epidural injections for spinal pain in the US fee-for-service Medicare population from 2000 to 2014. BMJ Open 6(12):e013042. https://doi.org/10.1136/bmjopen-2016-013042

29. Charlson ME, Pompei P, Ales KL, MacKenzie CR (1987) A new method of classifying prognostic comorbidity in longitudinal studies: development and validation. J Chronic Dis 40(5):373-383

30. Goz V, Errico TJ, Weinreb JH, Koehler SM, Hecht AC, Lafage V, Qureshi SA (2015) Vertebroplasty and kyphoplasty: national outcomes and trends in utilization from 2005 through 2010. Spine J: Off J North Am Spine Soc 15(5):959-965. https://doi.org/10.1016/ j.spinee.2013.06.032

31. American Academy of Orhopaedic Surgeons (2010) The treatment of symptomatic osteoporotic spinal compression fractures: guideline and evidence report. http://www.aaos.org/research/guidelines/ SCFguideline.pdf. Accessed June 1, 2017

32. McDonald RJ, Lane JI, Diehn FE, Wald JT (2017) Percutaneous vertebroplasty: overview, clinical applications, and current state. Appl Radiol 46(1):24-30
33. Beall DP, F. CM, Thomas SM, Easton R, Talati S, Goodman B, Datta D, Webb JR, Linville D EVOLVE (2017) A prospective multicenter evaluation of quality of life, pain \& activities of daily living outcomes for balloon kyphoplasty in the treatment of medicare patients with vertebral compression fractures. In: Evidence-based spine interventions seminar, Palm Springs

34. Barr JD, Jensen ME, Hirsch JA, JK MG, Barr RM, Brook AL, Meyers PM, Munk PL, Murphy KJ, O'Toole JE, Rasmussen PA, Ryken TC, Sanelli PC, Schwartzberg MS, Seidenwurm D, Tutton SM, Zoarski GH, Kuo MD, Rose SC, Cardella JF, Society of Interventional R, American Association of Neurological S, Congress of Neurological $\mathrm{S}$, American College of R, American Society of N, American Society of Spine R, Canadian Interventional Radiology A, Society of Neurointerventional S (2014) Position statement on percutaneous vertebral augmentation: a consensus statement developed by the Society of Interventional Radiology (SIR), American Association of Neurological Surgeons (AANS) and the Congress of Neurological Surgeons (CNS), American College of Radiology (ACR), American Society of Neuroradiology (ASNR), American Society of Spine Radiology (ASSR), Canadian Interventional Radiology Association (CIRA), and the Society of NeuroInterventional Surgery (SNIS). J Vasc Int Radiol: JVIR 25(2):171-181. https://doi.org/10.1016/j.jvir. 2013.10.001

35. Chandra RV, Meyers PM, Hirsch JA, Abruzzo T, Eskey CJ, Hussain MS, Lee SK, Narayanan S, Bulsara KR, Gandhi CD, Do HM PCJ, Albuquerque FC, Frei D, Kelly ME, Mack WJ, Pride GL, Jayaraman MV, Society of NeuroInterventional S (2014) Vertebral augmentation: report of the Standards and Guidelines Committee of the Society of NeuroInterventional Surgery. J Neurointerventional Surg 6(1):7-15. https://doi.org/10.1136/neurintsurg-2013-011012

36. De Laet C, Thiry N, Holdt Henningsen K, Stordeur S, Camberlin C (2015) Percutaneous vertebroplasty and balloon kyphoplasty - synthesis. Health Technology Assessment (HTA) Brussels: Belgian Health Care Knowledge Centre (KCE). KCE Reports 255Cs. https://kce.fgov.be/sites/default/files/page_documents/KCE_ 255C Percutaneaous vertebroplasty Synthesis.pdf

37. National Institute for Health and Care Excellence (2013) Percutaneous vertebroplasty and percutaneous balloon kyphoplasty for treating osteoporotic vertebral compression fractures. nice.org.uk/guidance/ta279. Accessed May 26, 2017

38. Swedish Council on Health Technology Assessment (2011) Percutaneous vertebroplasty and balloon kyphoplasty in treating painful osteoporotic vertebral compression fractures. https://www. ncbi.nlm.nih.gov/pubmedhealth/PMH0078702/pdf/PubMedHealth PMH0078702.pdf. Accessed May 26, 2017 